\title{
The Quality of Health Care System of Level 1 Hospitals in Northern Negros Occidental
}

\author{
Mary Je P. Geroso ${ }^{1}$ and Merlita V. Caelian ${ }^{2}$ \\ ${ }^{1}$ Corazon Locsin Montelibano Memorial Regional Hospital, Bacolod City, Philippines \\ 2University of Negros Occidental-Recoletos, Bacolod City, Philippines
}

\begin{tabular}{l} 
Article history \\
Submitted: 25 October 2020 \\
Revised: 2 November 2020 \\
Accepted: 16 November 2020 \\
\hline Keywords \\
Public Administration \\
Healthcare System \\
Quality \\
Level 1 Hospitals \\
Descriptive-Comparative \\
Northern Negros Occidental \\
Philippines
\end{tabular}

Introduction. Healthcare is a primary concern of everyone. The United Nations Sustainable Development Goals recognize the importance of healthcare, particularly ensuring healthy lives for all. Hence, healthcare organizations worldwide are interested in achieving better quality and performance (Khalifa \& Zabani, 2016). The Philippines supports this thrust towards achieving universal health coverage. The Philippine Health Agenda for 2016 to 2022 focus on recognizing the advancement and protection of public health. It has to discourse not just the universal and equitable delivery of health care but also the economic, social, and environmental dimensions of health concerns. The enactment of the Local Government Code provided that local government units deliver public health services with the national government's technical assistance through the Department of Health (DOH). Thus, this study describes and compares the level of quality of hospital healthcare system of Level 1 Hospitals in Northern Negros Occidental in the areas of hospital management, patient care management, and service delivery as assessed by implementers and patients' folks when they are taken as a whole and when grouped according to their designation. Likewise, it identified the challenges encountered by implementers and recommendations of patients' folks to improve the healthcare system of hospitals.

Methods. A descriptive- comparative research design was used to assess and compare the level of quality of healthcare systems in Level 1 Hospitals in Northern Negros Occidental in hospital management, patient care management, and health service delivery. The respondents of the study were the 82 implementers (doctors, nurses, administrative staff) and 32 patients' folks identified thru stratified random sampling. The data were generated from a survey using a researcher-made survey questionnaire based on the Department of Health (DOH) Standard Indicators for Hospital (2018). The results were computed using the Mean, Standard Deviation, frequency count, percentage distribution, and Kruskal-Wallis $\mathrm{H}$ test to analyze the data.

Results. The findings revealed that the level of quality of the hospital healthcare system of Level 1 Hospitals in Northern Negros Occidental is high, which means that it is very good. When assessors are grouped according to designation, the finding was also high. There was no significant difference in the level of quality of the healthcare system in Level 1 Hospitals when assessors are grouped according to designation. Among the challenges encountered by implementers is the overwhelming number of patients availing of healthcare services, coupled with a lack of medical professionals (Aikins, Ahmed, \& Adzimah, 2014). It was revealed that many of the patients who seek care in the hospitals are treatable in the primary health care institutions such as barangay health stations and the rural health units. Thus, how to overcome the health-seeking behavior of patients is a primary issue for health care professionals. Other challenges encountered by implementers concern organizational issues such as leadership and management, human resource management, and health service delivery. However, most of it is on patients' access to health care. Patients' folks recommended for the continued delivery of excellent, quality healthcare services supportive of the study of Wavomba and Sikolia (2015).

Conclusion. To sustain the quality of the healthcare system of Level 1 Hospitals in Northern Negros Occidental, government support, specifically financing, is necessary not only from the provincial government but also from the municipality or city where it is located not to discount the support from the national government. Challenges encountered by implementers on the overwhelming number 
of patients due to their health-seeking behavior implied that the healthcare system in the barangays and municipalities need to be strengthened. Recommendations are contained in the proposed program to improve the quality of the health care system of Level 1 Hospitals that includes policy change and reform in the healthcare system.

Practical Value of the Paper. The study significantly contributes to the few existing literature on the level of quality of healthcare systems in government-owned hospitals. The study's findings provided baseline information to hospital administrators and chiefs of hospitals in the formulation of realistic health care programs containing policy interventions on health system functioning and performance.

\section{References}

Aikins, I., Ahmed, M., \& Adzimah, E. D. (2014). Assessing the role of quality service delivery in client choice for healthcare: a case study of bechem government hospital and green Hill Hospital. European Journal of Logistics Purchasing and Supply Chain Management, 2(3), 1-23.

Al-Hussami, M., Al-Momani, M., Hammad, S., Maharmeh, M., \& Darawad, M. (2017). Patients' perception of the quality of nursing care and related hospital services. Health and Primary Care, 1(2), 1-6.

Angerer, A., \& Früh, M. (2013). The Impact of Process and Change Management Practices on Hospitals Operations Performance and Staff Satisfaction. In EURAM European Academy of Management Conference. Istanbul.

D'Cunha, S., \& Suresh, S. (2015). The measurement of service quality in healthcare: a study in a selected hospital. International Journal of Health Sciences and Research, 5(7), 333-345.

Dong, W., Zhang, Q., Yan, C., Fu, W., \& Xu, L. (2017). Residents' satisfaction with primary medical and health services in Western China. BMC health services research, 17(1), 298.

Gabutti, I., Mascia, D., \& Cicchetti, A. (2017). Exploring "patient-centered" hospitals: a systematic review to understand change. BMC health services research, 17(1), 364.

Groene, O. (2011). Patient centredness and quality improvement efforts in hospitals: rationale, measurement, implementation. International Journal for Quality in Health Care, 23(5), 531-537.

Khalifa, M., \& Zabani, I. (2016). Utilizing health analytics in improving the performance of healthcare services: A case study on a tertiary care hospital. Journal of Infection and Public Health, 9(6), 757-765.

Wanjau, K. N., Muiruri, B. W., \& Ayodo, E. (2012). Factors affecting the provision of service quality in the public health sector: A case of Kenyatta national hospital.

Wavomba, P., \& Sikolia, S. F. (2015). Research in the quality of service delivery in public hospitals, Kenya. Journal of Pharmacy and Biological Sciences, 10(6).

\section{Correspondence:}

Mary Je P. Geroso [mj.geroso@gmail.com]

https://orcid.org/0000-0003-0594-1750 